International Journal of Linguistics, Literature and Culture
Available online at https://sloap.org/journals/index.php/ijllc/
Vol. 5, No. 6, November 2019, pages: 92 101
$\begin{aligned} & \text { ISSN: 2455-8028 } \\ & \text { https://doi.org/10.21744/ijllc.v5n6.792 }\end{aligned}$

\title{
The Ellipsis of Grammatical Functions in Coordinative Structure of Japanese Language
}

\section{Article history:}

Received: 09 May 2019

Accepted: 30 September 2019

Published: 06 November 2019

\section{Keywords:}

anaphoric;

cataphoric;

controlled;

controller;

ellipsis;

grammatical function;

\begin{abstract}
The discussion in this paper is focused on the ellipsis of grammatical functions in Japanese covering that of the function of grammatical of coordinative structure. The data analyzed in this paper were taken from Japanese corpus data. The concept of ellipsis was taken from Quirk et al., (1985), Makino \& Tsutsui, (1994), and Verhaar (1981). The ellipsis from Quirk et al (1985) was applied the concept of recoverability from the grammatical point of view: (1) textual recoverability, (2) situational recoverability, and (3) structural recoverability. The qualitative and synchronic descriptive method was employed in this study. A qualitatively descriptive method was employed to explain and describe the coordinative sentence, whereas the synchronic approach was used to cover the current language phenomena. The findings show that in the coordinative structure, ellipsis of the function of grammatical subject, ellipsis the function of predicate and ellipsis of the function of object took place. Ellipsis of the function of grammatical in the coordinative structure can be anaphoric or cataphoric. It is called anaphoric because the ellipsis takes place rightward, the controlling constituents are located in the first clauses and the controlled constituents are located in the second clause. It is called cataphoric because the controlling constituents are located in the second clauses and the controlled constituents are located in the first clauses.
\end{abstract}

2455-8028 ${ }^{\circledR}$ Copyright 2019. The Author. This is an open-access article under the CC BY-SA license (https://creativecommons.org/licenses/by-sa/4.0/) All rights reserved.

\footnotetext{
Author correspondence:

Made Ratna Dian Aryani,

Japanese Department, Udayana University, Denpasar, Indonesia.

Email address: dian_aryani@unud.ac.id
}

\section{Introduction}

Nitta (1997), classifies Japanese types of sentences in two kinds, namely 1) based on structure and 2) based on meaning. Based on the structure, the sentence consists of two types, namely (a) which does not have a predicate element, and (b) which has a predicate element. Elements that have a predictive structure can be divided into two, namely (1) tanbun (single sentence) is a sentence that has only one clause and (2) fukubun (compound / complex

${ }^{\mathrm{a}}$ Udayana University, Denpasar, Indonesia 
sentences) is a sentence consisting of two or more clauses. One clause consists of only one predicate and only has one event, therefore, the clause in fukubun consists of the main clause or parent sentence, and subordinate clauses or clauses. Consider the following examples quoted from (Sutedi, 2003; Ningsih et al., 2018; Agustini \& Mataram, 2017).

(1) Tanaka wa Nihon jin desu.

Tanaka-Nom Japanese-Cop

'Tanaka is Japanese.'

(2) watashi wa kaze o hiite, gakkou o yasunda.

i-Nom a cold , school-Ak leave-past

'Because of a cold, I didn't go to school.'

Example (1) consists of one clause and only informs one thing, Tanaka is Japanese. Example (2) consists of two clauses, namely [watashi wa gakkou o yasunda] 'not entering school' as the main clause and [kaze o hiite] 'entering the wind/cold' as a subordinate clause.

Sentences with a coordinative structure in combining clauses can be done using conjunction and also without a conjunction. The coordinative conjunction used to combine the clauses is [ga] 'but', [soshite, sorekara] 'next', [KK-te] (continued form of the predicate in the form $\sim$ te), [Adj-te] (continued form adjectives $\sim$ te), and [Kop-te] (copula in the connective form) (Makino \& Tsutsui, 1994). Consider the following example:

(3) Tsuma wa itsumo genki desu. Soshite ryouri ga jouzu desu.

My wife-Nom always healthy-Cop. And cooking-Nom good-Cop

'My wife is always healthy and good at cooking.'

(Souko et al., 2000)

(4) biiru 2 hon, sorekara osake mo kudasai.

bir 2 bottles, and sake too please

' 2 bottles of beer, and sake too please.'

( The Nihongo no Jaanaru edisi Februari 2003)

(5) Wan-san wa Chuugoku jin de, Kimura-san wa Nihon jin desu. Wan-Nom Chinese Cop-te Kimura-Nom Japanese Cop

'Wan is Chinese while Kimura is Japanese.'

(Makino \& Tsutsui, 1994)

Each clause combined with coordinative conjunction is a free clause, meaning that the clauses can stand alone without being tied to another line. In other words, the syntactic position of each clause is the same.

Besides using conjunctions, coordinative sentences can also be made without using conjunctions. The nature of such constituent relations is called paratakstis. Parathesis is a combination of clauses with clauses without using formative conjunctions (Kaswati Purwo, 1990).

(6) sakura wa Nihon no sinboru da. Minna ni ai sarete iru. sakura-Nom Japan-Pem symbol-Cop. Everyone-Dat loved-Morf(pasive)

' Sakura is a Japanese symbol (which is loved by everyone).'

(Makino \& Tsutsui, 1994)

The absence of a constituent in a sentence is not an obstacle to being able to fully understand the sentence. This is due to the existence of a binding thread that connects a proposition with other propositions in speech or writing (Dardjowidjojo, 1986). Language tools that play a role in creating a combination of this unit are called cohesion (Halliday \& Hasan, 1976).

Aryani, M. R. D. (2019). The ellipsis of grammatical functions in coordinative structure of Japanese language. International Journal of Linguistics, Literature and Culture, 5(6), 92-101. https://doi.org/10.21744/ijllc.v5n6.792 
Judging from the interclausal relations in sentences, cohesion can be realized through (a) deletion, (b) pronominal usage, and (c) re-mention. Cohesion in inter-clausal relations in constituents with reference can refer to subject, predicate or object constituents. Consider the following example:

(7) Taro-san wa uchi e kaette, soshite sugu Taro-Nom home-Loc go , and

gakkoo e ikimasu.

school-Dat go-future.

'Taro went home, then immediately went to school.' $\emptyset$ immediately $\varnothing$

(DDLBJ, 2003)

Example (8) above, from written language, shows the existence of omission of the subject's grammatical function and nominative marker (Nom) wa in the second clause. Imposing a constituent in one sentence can be known to be a universal phenomenon. Looking at the three Japanese characteristics that are interrelated in the formation of sentence structure, it is interesting to study.

\section{Materials and Methods}

This research is a qualitative descriptive study. The matching method is a method of analysis that determines the outside, detached, and not part of the language in question. Researchers use advanced techniques in the form of matching techniques in the form of determining the determining elements. This method is used to find out and select inappropriate language elements (not in accordance with Japanese language norms). The data source taken from Japanese corpus, that is www.kotohona.shonagon.go.jp

\section{Theory}

The research in this article applies the ellipsis concept from Quirk et al., (1985), to analyze lapses in the coordinative sentence structure. In addition, there are very few researches that specifically address lapses related to Japanese, especially regarding the character of the grammatical function and the possibility of repetition.

Quirk et al., (1985), state that "ellipses are purely a surface phenomenon" which is grammatical removal. The principle difference regarding lapses in the concept of Quirk et al., (1985) is the enactment of the principle of "recoverable" from the context as the main requirement for the lapse. The intended context is the linguistic context, namely part of a text; but it is also another source of relaxation which is certainly from repetition ". This study only classifies ellipsis according to Quirk et al., (1985), based on the type of textual repetition and functional type only in accordance with the object of research.

\section{Results and Discussions}

A coordinative structure sentence is formed by combining two or more equal clauses. Merging clauses can be done by using conjunctions and can also be without using conjunctions. The coordinative sentence of Japanese uses conjunctions: ga 'but', soshite, sorekara 'next', [V-te] (continued form of predicate in the form te), [Adj-te] (adjunctive form $\sim t e$ ), and [Cop-te] (copula in connective form) (Makino \& Tsutsui, 1994; Darlina, 2016).

a) Conjunctions $[\mathrm{ga}]$

Below will be described some data combining coordinative clauses with conjunctions [ga] 'but' and the process of impingement in number (a) and repetition of lapses in number (b).
(1a) Yama no
seikatsu wa
amari benri
ja arimasen ga,
Mountain-Gen life-Nom
not very practical
but,
shizuka desu.
quiet-Cop 
'Life on the mountain is not very practical but, quiet.'

(Souko et al., 2000)

(1b) Yama no seikatsu wa amari benrija arimasen ga, Ø [yama no seikatsu wa] shizuka desu.

'Life on the mountain is not very practical but, [life on the mountain] quiet.'

(2a) Kanaiwa Furansugo o hanaseru ga, My wife-Nom French-Ak speak-Morf (bentuk bisa) but,

watashi wa hanasenai.

I am Nom not (cant speak)-Morf (-neg) 'My wife can speak French, but I cannot.'

(Makino \& Tsutsui, 1994)

(2b) Kanai wa Furansugo hanaseru ga, watashi wa $\emptyset$ [Furansugo o] hanasenai. 'My wife can speak French, but I cannot [French].'

The data above uses the conjunctive [ga] 'but', in the example (1) and (2) there is a grammatical function of the subject and the combination of the clause uses intransitive clause + intransitive clause, while in data (3) there is an objective function and use transitive clause + transitive clause. Immersion occurs in the grammatical function of the object. The conjunctions are used to express comparative sentences.

b) Conjunctions [soshite]

Below will be described several examples of combining coordinative clauses with conjunctions [soshite]] next / and', and the process of impingement in number (a) and repetition of lapses in number (b).

(3a) Machi no seikatsu wa omoshiroi desu ne. Soshite benri desu. city-Gen life-Nom interesting-Cop . And practical-Cop 'Life in the city is interesting, and practical.'

(Souko et al., 2000)

(3b) Machi no seikatsu wa omoshiroi desu ne. Soshite $\emptyset$ [machi no sekatsu wa benri desu.

'Life in the city is interesting, and [life in the city] practical.'

(4a) Tsuma wa itsumo genki desu. Soshite ryouri ga jouzu desu. My wife-Nom always healthy-Cop. And cooking-Nom good-Cop 'My wife is always healthy and good at cooking.'

(Souko et al., 2000)

(4b) Tsuma wa itsumo genki desu. Soshite $\emptyset[$ tsuma $\boldsymbol{w a}]$ ryouri ga jouzu desu. 'My wife is always healthy and [my wife] good at cooking.'

Data (3), and (4) use the conjunctive [soshite] 'next/last 'and in the example (3) and (3) there is an overthrow of the subject's grammatical function. Examples (3) and (4) are combinations of intransitive clauses + intransitive clauses. The conjunction of 'soshite' is a conjunction for equivalent sentences. Data (3) uses particle ne at the end of a sentence, used to emphasize feelings such as sympathy of the speaker to the other person, or at the time of expecting approval (affirmation of something) the other person is talking to.

c) Conjunctions [sorekara]

Below will be described some data combining the coordinative clause with the conjunction [sorekara] " next/next/ last ', and the process of impingement in number (a) and the repetition of lapses in number (b).

Aryani, M. R. D. (2019). The ellipsis of grammatical functions in coordinative structure of Japanese language. International Journal of Linguistics, Literature and Culture, 5(6), 92-101. https://doi.org/10.21744/ijllc.v5n6.792 
(5a) Oosaka kara Okinawa made 45 jikan kakarimashita.

Oosaka fromi Okinawa to 45 hours takes time-past,

sorekara isshuukan ryouko shimashita.

And 1 week excursion-past

'It takes 45 hours from Oosaka to Okinawa, then an excursion for 1 week.'

(Souko et al., 2000)

(5b) $\varnothing[$ Watashi wa $]$ Oosaka kara Okinawa made 45 jikan kakarimashita, sorekara isshuukan ryouko shimashita.

' $[I]$ It takes 45 hours from Oosaka to Okinawa, then an excursion for 1 week.'

(6a) biiru 2 hon, sorekara osake mo kudasai.

bir 2 bottles, and sake too please

' 2 bottles of beer, and sake too please.'

(The Nihongo no Jaanaru edisi Februari 2003)

(6b) Biiru $\varnothing[\boldsymbol{\emptyset}] 2$ hon $\emptyset[$ kudasai $]$, sorekara osake mo $\emptyset[2$ hon $]$ kudasai.

'[please $] 2$ bottles of beer, and sake [ 2 bottles] too please.'

Examples (5) and (6) use the conjunctive [sorekara] 'next/last ', and in the data (5) there is an overthrow of the subject's grammatical function. In the data there is a combination of intransitive clause + transitive clause and intransitive clause + intransitive clause, while in data (6) there is a particle [o] and form of politeness [kudasai] 'please' in the first clause, combining clauses is a transitive + transitive clause. In reconstruction (6b) the repetition is unusual or not called back, because the reader/speaker is considered to have understood that the poor constituent is the first pronoun.

In the process of combining the Japanese clause, there is often a first pronoun or second pronoun. This happens because in the process of combining the coordinative structure clause, the reader or listener has been considered to know so that the first pronoun or second pronoun, there is no need to mention or write back. If the first pronominal or second pronoun remains included, then the Japanese sentence becomes unusual.

d) Conjunctions form [Cop-te]

Below will be described some data combining the coordinative clause with the conjunction pattern [Kop-te] 'and / while' and the process of imposition in number (a) and the repetition of lapses in number (b).

(7a) Edo jidai wa 1603 nen kara 1868 nen made de,

Edo period-Nom 1603 years from 1868 years to-Cop,

yaku 260 nen arimashita.

approximately 260 years ada

'The Edo period from 1603 to 1868 , and there were approximately 260

years. '

(Souko et al., 2000)

(7b) Edo jidai wa 1603 nen kara 1868 nen made de, $\varnothing$ [Edojidai wa] yaku 260

nen arimashita.

'The Edo period from 1603 to 1868 , and [Edo period] there were

approximately 260 years.

(8a) Wan-san wa Chuugoku jin de, Kimura-san wa Nihon jin desu.

Wan-Nom Chinese Cop-te Kimura-Nom Japanese Cop

'Wan is Chinese while Kimura is Japanese.'

(Seichi \& Tsutsui, 1997) 
Data (7) and (8), using conjunctions with patterns: [Copula-te] which means 'is'. The pattern is used to combine sentences, one of which (the previous clause) is a non-predicate intransitive sentence. Because the example above uses the pattern conjunction: [Copula], the merging of the clause can or may not. This depends on the topic of the sentence in each clause. In the example (7) - (8) there can be lapsed or not occur.

e) Conjunctions form [V-te, $V$-te]

Below will be elaborated on some data combining coordinative clauses with conjunctions [KK-te, KK-te] 'then / and' and their imposition process in number (a) and repetition of lapses in number (b).

(9a) Norenai hito wa oinori o shite,

Go up can't-Morf (neg) people-Nom pray-Ak do-Morf

saigo no toki o machimashita.

last-Gen time-Ak wait-past

'People who can't go up pray, then wait for the last hour.'

(Souko et al., 2000)

(10a) Oujosama ga hitori de Rooma no machi ni dete, King daughter-Nom alone Roma-Gen city-Dat out-Morf

shinbunkisha to iroirona keiken o suru ohanashi desu.

Reporters to a variety experiences-Ak do story-Cop

'The king's daughter came out of Rome alone, then told a variety of

experiences to reporters. '

(Souko et al., 2000)

Examples (9) and (10) use pattern conjunctions [V-te, V-te] and are a special process of combining clauses. It is said specifically because the pattern is used to show the sequence of work carried out sequentially, and even though there is a lapse of the grammatical function of the subject in each data, the lapse is not returned situationally. If the missing constituents are still repatriated, then the sentence will be unusual and unacceptable in Japanese. It is said to be unusual, because in Japanese for the process of combining form clauses [V-te, V-te] there is no repetition in the form of nomination because the constituents of the grammatical function of the subject have been mentioned first. The merging in the sentence above occurs between the transitive clause + the transitive clause.

f) Conjunctions form $[$ Adj-te $]$

Below will be described some data combining coordinative clauses with conjunctions [Adj-te] 'but', and the process of impingement in number (a) and repetition of lapses in number (b).

(11a) Sono koro tsukurareta fune no naka dewa ichiban ookikute, it time artificial ship-Gen in-Nom most large-Morf

subarashikute, zettai ni shizumanai fune da to iwaremashita.

baru-Morf zink-neg ship said

'It was said that at that time the most large, new and definitely no artificial

ship would sink

(Souko et al., 2000)

(11b)* $\varnothing$ Sono koro tsukurareta fune no naka dewa ichiban ookikute, subarashikute, zettai ni shizumanai fune da to iwaremashita.

'It was [people] said that at that time the most large, new and definitely no artificial ship would sink .

(12a) Ano otoko no hito wa hayaku booto ni noritakute, The man-Gen peaple-Nom quickly lifeboat-Dat get on-Morf,

Aryani, M. R. D. (2019). The ellipsis of grammatical functions in coordinative structure of Japanese language. International Journal of Linguistics, Literature and Culture, 5(6), 92-101. https://doi.org/10.21744/ijllc.v5n6.792 
kenka o shimashita.

fight-past

'The man wants to get on the lifeboat quickly, fight.'

(Sawada et al., 2000)

(12b)* Ano otoko no hito wa hayaku booto ni noritakute, $\varnothing$ kenka o shimashita.

'The man wants to get on the lifeboat quickly, [the man] fight.

Data (11) and (12) use pattern conjunctions: [Adj-te] and are a special process of combining clauses. It is said specifically because the pattern is used to show the connecting form of Japanese type I or type II adjectives. The pattern of adjunctive forms is 'and', but the pattern of the Japanese adjunctive form cannot use the particle [to] 'and' in the sentence. In the data above, there is a grammatical function of the subject, but not recovery.

That is because if the missing constituents are still repatriated, it will become unusual and unacceptable in Japanese. The merger occurs between intransitive clauses + intransitive clauses.

\section{g) Paratactic}

Below will be described some data combining coordinative clauses with "no" conjunctions (parataktis) "and", and the process of impingement in number (a) and repetition of ellipses in number (b).

(13a) Jon wa kikaikougaku o, Nanshii wa denkikougaku o John-Nom engineering mechanical-Ak, Nancy-Nom electricalmechanical-Ak

senkoushite iru. majored- doing

'John majored in mechanical engineering and Nancy in electrical engineering.'

(Kougaku, 1999)

(13b) Jon wa kikaikougaku o $\emptyset$ [senkoushite iru ], Nanshii wa denkikougaku o senkoushite iru.

'John [mengambil jurusan] teknik mesin dan Nancy mengambil jurusan teknik elektro.'

(14a) Kinou wa suteki o tabeta. Totemo oishikatta. Yesterday-Nom steak-Ak ate-Morf . Very delicious-Morf. 'Yesterday ate steak. Very delicious.'

(Yoko Tomisaka, 1997)

(14b) Kinou wa suteki o tabeta. $\emptyset[$ Suteki wa $]$ Totemo oishikatta. 'Yesterday ate steak. [Itu/Steak $]$ Very delicious.'

The data (13a) are two clauses, but the method of combining the clause uses a sloppy technique, namely the passing of the grammatical function of the same predicate, which is 'taking majors'. The function of the predicate that is applied is the function of the predicate in the first clause, because in Japanese if the phrase that references the second clause is set it will be unacceptable in Japanese. Data (14a) which is applied is the grammatical function of the subject, which shows the function of the object [suteki] 'cute/good' in the first sentence.

Data (13) and (14) above are inter-lausal relationships with the disappearance of part of the clause. In the Japanese language data above, such lapses can occur in the predicate or subject grammatical functions. Data (21) lapses are kataforis. For inter-lausal relations in the presence of complementary functions or grammatical functions of information are compulsory and will usually be mentioned once in a sentence so that there are no repetitions or referential constituents. 
The clause that begins with the coordinators [ $g a$, shikashi] 'but' and [Kop-te] 'and' Japanese will produce an unacceptable clause if the clause is placed at the beginning of the sentence. For example:

(15a) Ano otoko wa totemo aisou ga ii desu.

that man-Nom very hospitality-Nom good-Kop

ga, amari shinyou shite wa dame desu yo.

but, not untrustworthy-Nom do not-Kop .

'The man's hospitality is very good, but his trust is not good (untrustworthy person).'

(Kimura \& Shinichi, 1998)

$(15 b)^{*} \mathrm{Ga}$, amari shinyou shite wa dame desu you. Ano otoko wa totemo aisou ga ii desu.

(16a) Kanojou wa utsukushii. Shikashi seikaku ga yokunai. She-Nom beautiful. But character-Nom good-neg 'She is beautiful. But his character is not good.'

(Kimura \& Shinichi, 1998)

(16b)* Shikashi, seikaku ga yokunai. Kanojou wa utsukushii. but, personallity-Nom not good. She-Nom beautoiful. 'But his personality is not good. She is beautiful.'

Likewise in Indonesian, a clause that begins with the coordinator "and", "but" and "or" will produce an unacceptable sentence if the clause is placed at the beginning of the sentence.

\section{Nature of Disappearance}

The results of the analysis of the data through the process of combining clauses/sentences above state that subject lapses are always anaphoric (rightward impingement. The right direction occurs in the coordinative sentence structure. Consider the example below:

(1a) Machi no seikatsu wa omoshiroi desu ne. Soshite $\boldsymbol{\emptyset}_{\mathrm{i}}$ benri desu. City-Gen life-Nom interesting-Kop . Furthermore $\boldsymbol{\emptyset}_{\text {i }}$ practical-Kop

'Life in the city is interesting. Furthermore practical.'

(Makino et al., 2000:14 I)

(1b)* $\emptyset_{\text {i }}$ omoshiroi desu ne. Soshite machi no seikatsu wa benri desu.

' $\emptyset_{\mathrm{i}}$ interesting. $\quad$ Furthermore city-Gen life-Nom practical-Kop.'

Sentences (1b) are examples of unacceptable impingement sentences in Japanese because sentences (1b) are sentences that each have their own meaning and are not related as a coordinative structure.

Aryani, M. R. D. (2019). The ellipsis of grammatical functions in coordinative structure of Japanese language. International Journal of Linguistics, Literature and Culture, 5(6), 92-101. https://doi.org/10.21744/ijllc.v5n6.792 
(1a)

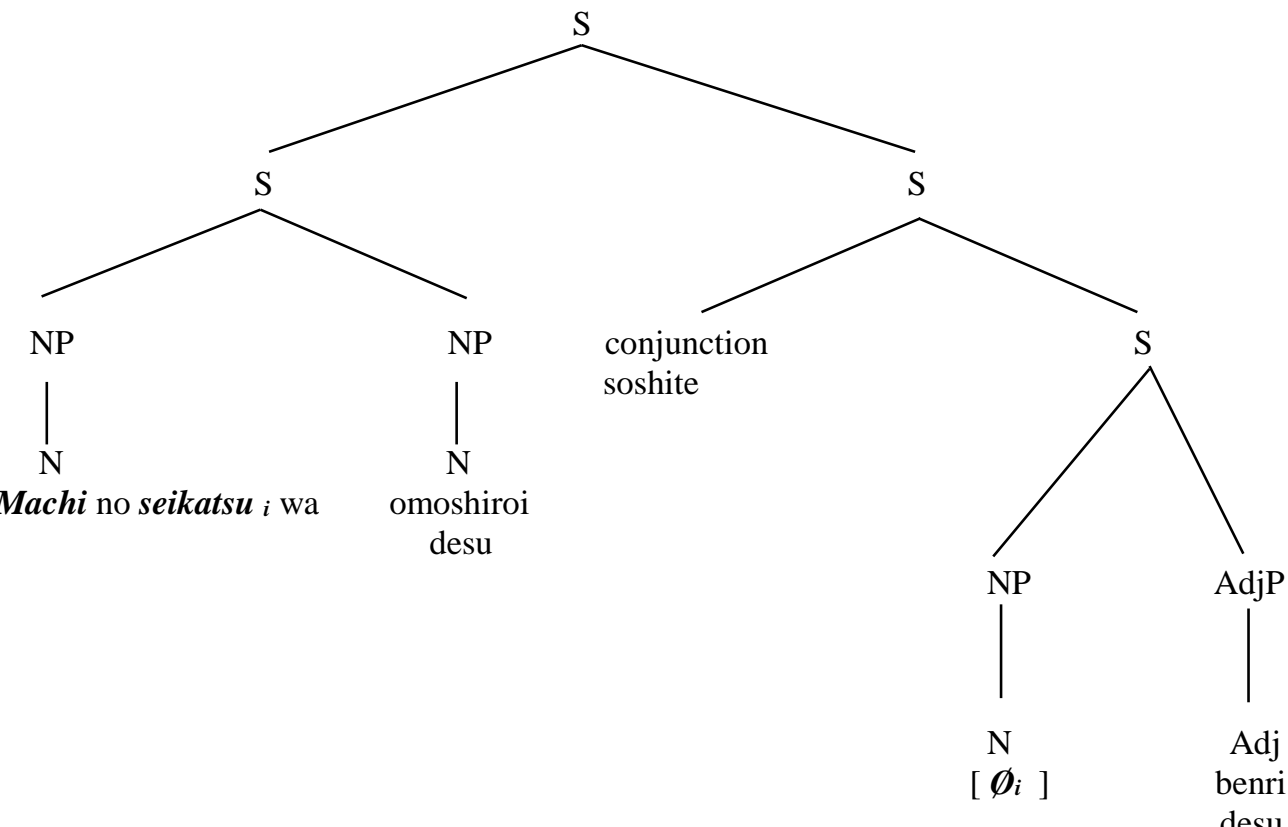

In the transformation above, the constituent [machi no seikatsu wa] is a controlling constituent located in the first clause, and the controlled constituent $[\varnothing]$ is located in the second clause.

\section{Conclusion}

From the discussion of lapses in a coordinative structure, it can be concluded that lapses in a coordinative structure can occur in the subject's grammatical functions, grammatical functions of objects and grammatical functions of predicates. In completing complementary functions and information functions not found in the analysis of the Japanese coordinative structure. This is due to the presence of complementary constituents and mandatory information on each clause. Imposing the grammatical function of the subject and imposing the grammatical function of the object on the coordinative structure, there is an eruption towards the right. Therefore, the keforisan nature of the subject of grammatical functions of the subject and the passing of the grammatical functions of the object are anaphoric. Meanwhile, the grammatical function of the predicate in the Japanese coordinative structure, going to the left, is said to be kataforis. If the location of each controlling constituent or its controlled constituents is not suitable, then the coordinative sentence becomes unacceptable in Japanese. The first pronominal or second pronoun in Japanese is very often done because lapses in constituents that are Japanese in reference are made to avoid the repetition of the same constituents, which eventually becomes ineffective and unacceptable in Japanese. Imposing mandatory grammatical functions of the subject to show politeness in Japanese.

\section{Conflict of interest statement}

The author declared that she has no competing interests.

Statement of authorship

The author has a responsibility for the conception and design of the study. The author has approved the final article.

\section{Acknowledgments}

The authors would like to thank the reviewer for their consideration of the further process of the present paper. Thanks to the editor of IJLLC for the valuable support, time as well as advice. 


\section{References}

Agustini, N. P., \& Mataram, I. K. A. (2017). Effect induction bio hormone on production and content of nutritional substances on tomato fruit variety cherry small fry and cherry japan. International Research Journal of Engineering, IT \& Scientific Research, 3(3), 103-114.

Dardjowidjojo, S. (1986). Benang Pengikat Wacana. Pertemuan Ilmiah Regional, MLI. Jakarta.

Darlina, L. (2016). Relational grammar of passive in Japanese. International Journal of Linguistics, Literature and Culture, 2(2), 167-178.

Halliday, M. H., \& Hasan, R. (1984). R.(1976): Cohesion in English. In Mei-yun Yue, Cohesion and the Teaching of EFL Reading. Forum (Vol. 31, No. 02, pp. 2-20).

Kimura, S., Kusafuka, K., \& Shimizu, H. (1998). Optimum film compensation of viewing angle of contrast in inplane-switching-mode liquid crystal display. Japanese journal of applied physics, 37(9R), 4822.

Kougaku, X. S. K., Namioka, T., \& Yamashita, K. (in Japanese),(1999), 309.

Makino, S., \& Tsutsui, M. (1994). Dictionary Of Basic Japanese Grammars. The Japan Times.

Makino, S., \& Tsutsui, M. (2001). A dictionary of intermediate Japanese grammar: Nihongo bunpou jiten (chuukyuu hen). Japan Times.

Ningsih, E., Emzir, -, \& Hidayat, R. S. (2018). Dynamic equivalence assessment of Japanese comic (manga) "garasu no kamen" into Indonesian language translation "topeng kaca" (the glass mask). International Journal of Linguistics, Literature and Culture, 4(4), 53-68. https://doi.org/10.21744/ijllc.v4n4.263

Nita,Y. (1997). Gendaigo no Bunpoo/ Bunpooron", in Nihongo Yousetsu. Tokyo: Hitsuji Shoubou

Purwo, B. K. (1990). Pragmatik dalam pengajaran Bahasa.

Quirk, R., Greenbaum, S., Leech, G., \& Svartvik, J. (1985). 19919. A Comprehensive Grammar of the English Language.

Souko, O. (2000). Kehitysvammainen ja seksuaalisuus. Porin sosiaalialan oppilaitos.

Sutedi, D. (2003). Dasar-dasar linguistik bahasa jepang. Bandung: Humaniora.

Tomisaka, Y. (1997). Nihongo no Dansei to Josei no Kotoba. Tokyo: Aruku.

\section{Biography of Author}

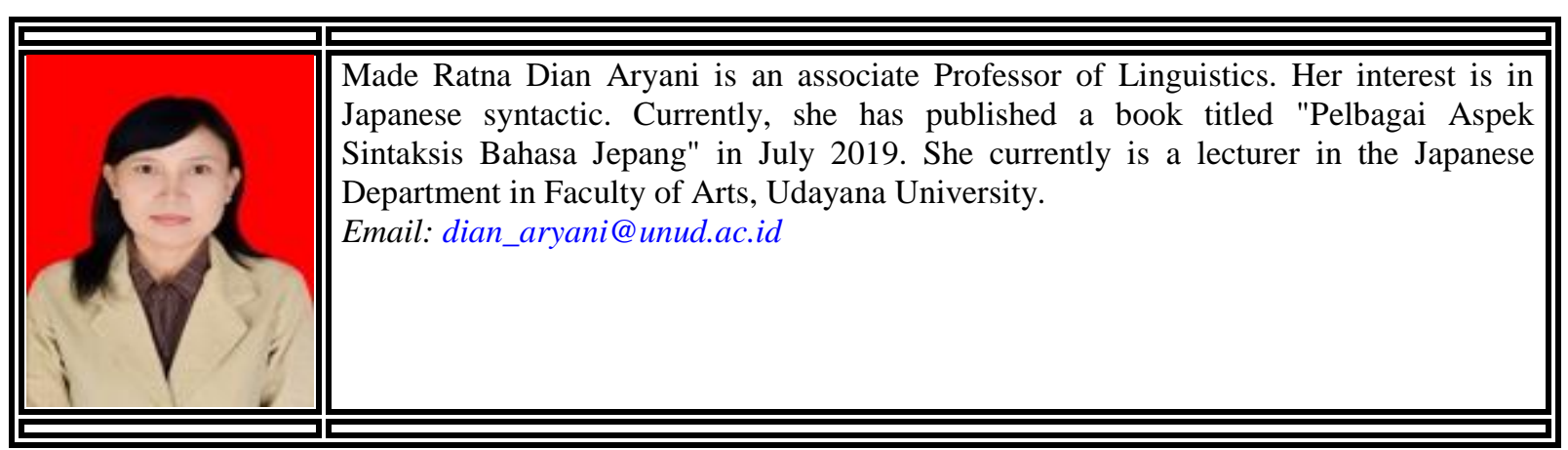

Aryani, M. R. D. (2019). The ellipsis of grammatical functions in coordinative structure of Japanese language. International Journal of Linguistics, Literature and Culture, 5(6), 92-101. https://doi.org/10.21744/ijllc.v5n6.792 